\title{
Frequency Distribution and Risk Factors of Helicobacter Pylori Infection in Patients with Gastric Problems in Mardan Pakistan
}

\author{
Rimsha, Mehwish Nawaz, Sulaiman Shams, Asifullah Khan, Hammad Hassan, Mohibullah Shah and \\ Sahib Gul Afridi*
}

Department of Biochemistry, Abdul Wali Khan University, Pakistan

Received: February 26, 2018; Published: March 08, 2018

*Corresponding author: Sahib Gul Afridi, Department of Biochemistry, Abdul Wali Khan University, Pakistan, Tel: 923349102565;

Email: drafridi@awkum.edu.pk

\section{Abstract}

Helicobacter pylori (H. pylori) are a common chronic infection that is responsible for causing several gastro duodenal diseases and accounts for $84.3 \%$ of Gastric Cancer. The proposed study aimed at finding frequency of $\mathrm{H}$. pylori infection and its associated risk factors in patients with gastric problems from Mardan, Khyber Pukhtunkhwa Pakistan. We carried out a cross-sectional study that included 200 subjects of age groups 11-50 years who underwent screening method of Immune Chromatographic Technique (ICT) in major hospitals of Mandan city. Results showed that 94 (47\%) subjects were found positive for $\mathrm{H}$. pylori in which males were $63(67 \%)$ and females were 31 (33\%).

Based on multivariate analysis frequency rate of $\mathrm{H}$. pylori was higher as 41 (43\%) subjects each in age groups 11-20 years and 21-30 years followed by $10(10.60 \%)$ with age group of 31-40 years and $2(2.12 \%)$ with age group of 41-50 years. Irrespective of age groups frequency rate was high in $30(31.19 \%)$ subjects infected withindigestion problem. Those subjects which were educated had higher frequency rate 68 (72.34\%) as compared to illiterate 26(27.65\%). Our study concluded that frequency of H. pyloriin Mardan was observed to be very high (47\%) among the subjects with gastric problems as compared to the prevalence worldwide and there had been a striking increase in males, younger and educated subjects.

Keywords: Helicobacter pylori; Frequency; Immune Chromatographic Technique

Abbreviations: RUT: Rapid Urease Test; PCR: Polymerase Chain Reaction; FISH: Fluorescent In Situ Hybridization; UBT: Urea Breath Test; ICT: Immune Chromatographic Technique; MMC: Mardan Medical Complex

\section{Introduction}

Helicobacter pylori (H. pylori) is a microorganism responsible for the most frequent and persistent bacterial infection worldwide. It is Gram-negative, spiral-shaped, microaerophilic bacterium that inhabits various areas of the stomach, particularly the atrium that was first discovered in 1982 and represents a key factor in the etiology of various gastrointestinal diseases, ranging from chronic active gastritis without clinical symptoms to peptic ulceration, gastric adeno-carcinoma, and gastric mucosa-associated lymphoid tissue lymphoma [1]. H. pylori infection is the most important risk factor for gastric cancer, and is estimated to account for approximately $80 \%$ in developing countries and less than $40 \%$ in developed countries [2]. The high prevalence of H. pylori infection and gastrointestinal disease in adults is closely related to $\mathrm{H}$. pylori infection during childhood [3]. The prevalence of infection among children ranges from $2.4 \%$ to $13.6 \%$ in developed countries and from $22.6 \%$ to $80 \%$ in developing countries.

This difference may be attributed to poor socioeconomic status and overcrowded conditions during childhood [4]. In general, H. pylori prevalence is higher in developing countries and declining in the United States and in Pakistan the prevalence of $\mathrm{H}$. pylori is $50-90 \%$ which is very high as compared to universal prevalence [5,6]. The prevalence remains high especially most in developing countries, in which poor sanitation and lack of hygiene appear to play a fundamental role in the dissemination of the bacteria. Global and regional $\mathrm{H}$. pylori prevalence have not been systematically reported until now. Different prevalence of $\mathrm{H}$. pylori has been observed in children of different ages for instance $72.38 \%$ in school children while $33 \%$ prevalence in children less than 6 years old 
[7]. The rate of Gastric cancer in male is about twice than that of females which could reflect sex-differences in the prevalence of $\mathrm{H}$. pylori [8]. H. pylori infection is more common during childhood, under the age of 5 years while in teen agers infection is rare [9]. Transmission of H. pyloriis still not entirely clarified but human-tohuman spread through oral-oral or fecal-oral route is thought to be the most plausible.

The fecal oral route has been considered an important form of transmission. The presence of $\mathrm{H}$. pylori in oral cavity is more frequent in seropositive subjects [10], and several studies from Brazil have consistently showed an association between gastric $\mathrm{H}$. pylori infection and the presence of this bacterium in the oral cavity. Moreover, the bacterium identified in the samples of the different sites within a given subject among all patients in one study [11]. And in up to $89 \%$ in another study [12], Were of identical genotype. Studies have shown the presence of $\mathrm{H}$. pylori in drinking water and the role of poor living conditions and sanitation in H. pylori infection, supporting an oral-fecal route of spread. [13]. the most striking biochemical characteristic of $\mathrm{H}$. pylori is the production of large quantities of unease. This enzyme digests urea to produce carbon dioxide and ammonia. In the presence of water this leads to the formation of Ammonium hydroxide [14].

In this way $\mathrm{H}$. pyloriis able to neutralize the acid in its direct Environment. Various diagnostic methods exist to detect infection. They include serologic tests, urea breath tests, stool antigen tests, and endoscopic biopsies which are available in hospital or clinic settings but the choice of one method or another depends on several factors, such as accessibility, advantages and disadvantages of each method, cost, and the age of patients. The diagnosis of H. pylori can be done by two methods invasive and non-invasive. Invasive method includes endoscopy and biopsy [histological examination, Rapid Urease Test (RUT), Polymerase Chain Reaction (PCR), and Fluorescent. In Situ Hybridization (FISH). Non-invasive methods include 13C, 14C Urea Breath Test (UBT), detection of $\mathrm{H}$. pylori antigen (Ag) in stool, and detection of antibodies (Abs) against $\mathrm{H}$. pylori in serum, and saliva [15].

Non-invasive methods are mostly serological methods, including the complement fixation test, the bacterial agglutination test, the passive hem agglutination test, the hem agglutination assay, immunoblotting and enzyme-linked immunoassays. One of the non-invasive techniques i.e. Immune Chromatographic Technique (ICT) is commonly used for the diagnosis of $\mathrm{H}$. pylori because of its low cost and easily availability at any laboratory. This study was aimed to evaluate the frequency of $\mathrm{H}$. pylori and its associated risk factors in patients with gastrointestinal problems through Immune Chromatographic Technique (ICT). This will be helpful in determining the burden of $\mathrm{H}$. pylori in our population, creating awareness and taking preventive measures against this ignored problem.

\section{Materials and Methods}

Study Subjects: A total number of 200 subjects aged between 10-50 years were recruited for this study from the Mardan Medical Complex (MMC) and other private laboratories in Mardan (Table 1).

Table 1: Distribution and Risk Factors of H. pylori in studied area.

\begin{tabular}{|c|c|c|c|c|c|c|}
\hline \multicolumn{7}{|l|}{ Parameters } \\
\hline \multirow{6}{*}{ Age } & Age Groups & Frequency & \multicolumn{2}{|c|}{ Arithmetic Mean } & \multicolumn{2}{|c|}{ Percentage } \\
\hline & $11-20$ & 41 & \multirow{5}{*}{\multicolumn{2}{|c|}{22.4}} & \multicolumn{2}{|c|}{$43.60 \%$} \\
\hline & $21-30$ & 41 & & & \multicolumn{2}{|c|}{$43.60 \%$} \\
\hline & & & & & \multicolumn{2}{|c|}{$10.60 \%$} \\
\hline & $31-40$ & 10 & & & \multicolumn{2}{|c|}{$2.12 \%$} \\
\hline & $41-50$ & 2 & & & & \\
\hline \multirow{2}{*}{ Gender } & Male & 63 & & & \multicolumn{2}{|c|}{$67 \%$} \\
\hline & Female & 31 & & & \multicolumn{2}{|c|}{$32.90 \%$} \\
\hline \multirow{2}{*}{ Literacy } & Illiterate & 26 & & & \multicolumn{2}{|c|}{$27.60 \%$} \\
\hline & Educated & 68 & & & \multicolumn{2}{|c|}{$72.30 \%$} \\
\hline \multirow{2}{*}{ Symptoms } & Headache & Body pain & Low appetite & Abdominal pain & Indigestion & Acidity \\
\hline & $11(11.70 \%)$ & $2(2.12 \%)$ & $23(24.46 \%)$ & $18(19.14 \%)$ & 30 (31.91\%) & $10(10.60 \%)$ \\
\hline
\end{tabular}

Data Collection: Data was collected over six months from October 2016 to March 2017. Blood samples were tested by laboratory technician expert using Immune Chromatographic Technique (ICT) method and were categorized on basis of sex, age, literacy rate and symptoms.

Method: The blood samples from the subjects were applied on ICT strips. The sample reacts with $\mathrm{H}$. pylori antigen conjugated to colored particles and precoated onto the sample pad of the test.
The mixture then migrates through the membrane by capillary action, and interacts with reagents on the membrane. If there are sufficient antibodies to Helicobacter pylori in the sample, a colored line will form at the test region of the membrane. The presence of this colored line indicates a positive result, while its absence indicates a negative result. The appearance of a colored line at the control region serves as a procedural control, indicating that the proper volume of sample has been added and membrane wicking has occurred. 
Statistical Analysis: The data obtained from the study was subjected to mean and percentage analysis. The data were also subjected to graphical representation according to mean percentage. All the statistical data were analyzed using software Microsoft excel version 2010.

Inclusion Criteria: The subjects who were facing the indigestion problems were considered as positives and were screened for $\mathrm{H}$. pylori by using Immune Chromatographic Techniques.

\section{Results}

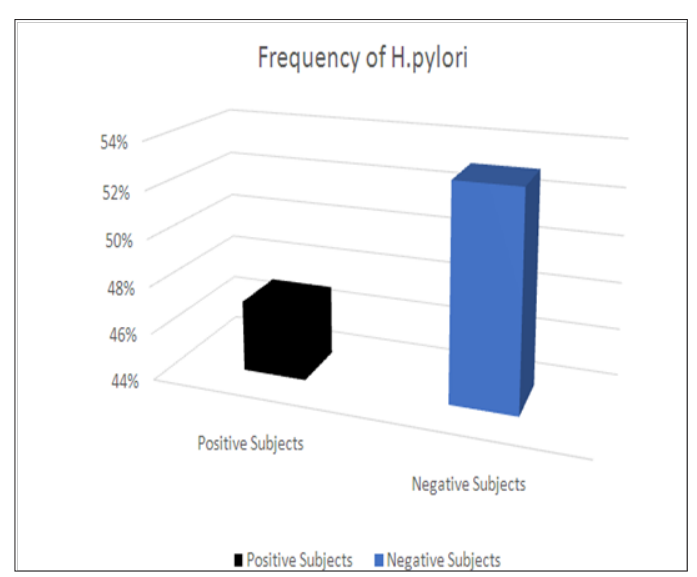

Figure 1: Frequency of $\mathrm{H}$. pyloriin local hospitals of Mardan.

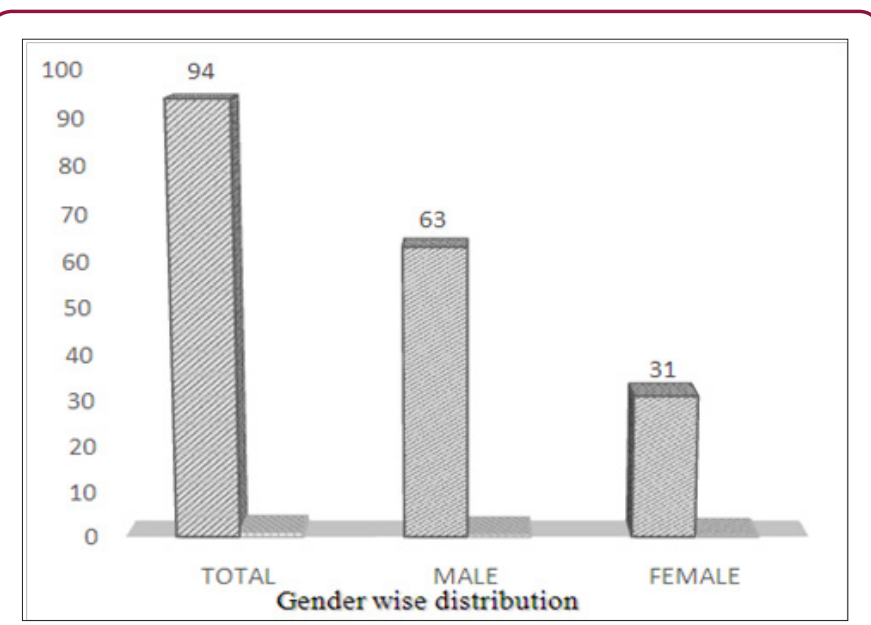

Figure 2: Frequency of $\mathrm{H}$. pylori on basis of gender.

Among 200 subjects 94 (47\%) were infected as shown in (Figures 1 \& 2) showed that $\mathrm{H}$. pylori prevalence rate in males was more $63(67 \%)$ as compared to females 31 (33\%). (Figure 3) showed prevalence rate of $H$. pylori was higher 41 (43\%) in subjects age groups 11-20 years and 21-30 years than subjects age groups 31-40 years and 41-50 years in which prevalence rate was $10(10.60 \%)$ and $2(2.12 \%)$ respectively. Irrespective of age groups prevalence rate was high in subjects 30 (31.19\%) infected withindigestion problem as compared to subjects infected with other symptoms,23(24.46\%) subjects presented low appetite, abdominal pain was in $18(19.14 \%)$ subjects, acidity problem was in $10(10.60 \%)$ subjects, $11(11.70 \%)$ subjects presented headache body pain were in $2(2.12 \%)$ subjects as shown in (Figure 4$)$. Upon classification of the study subjects according to literacy rate 68 $(72.34 \%)$ were found educated and $26(27.65 \%)$ were illiterate as shown in (Figure 5).

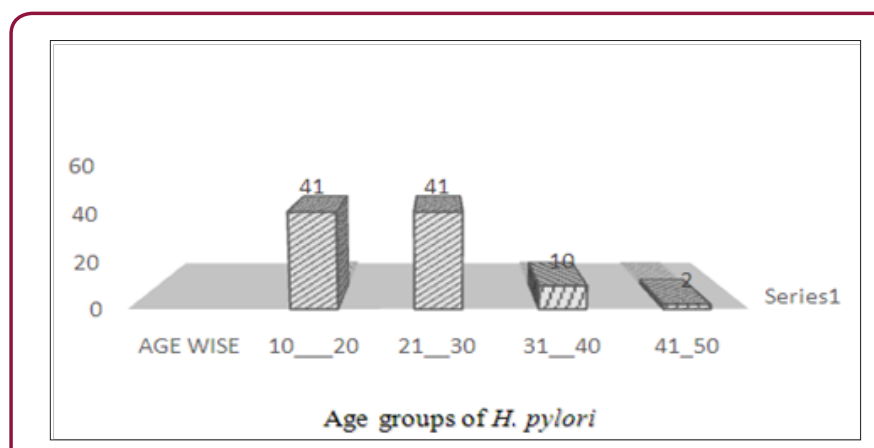

Figure 3: Frequency of $\mathrm{H}$. pylori on the basis of Age.

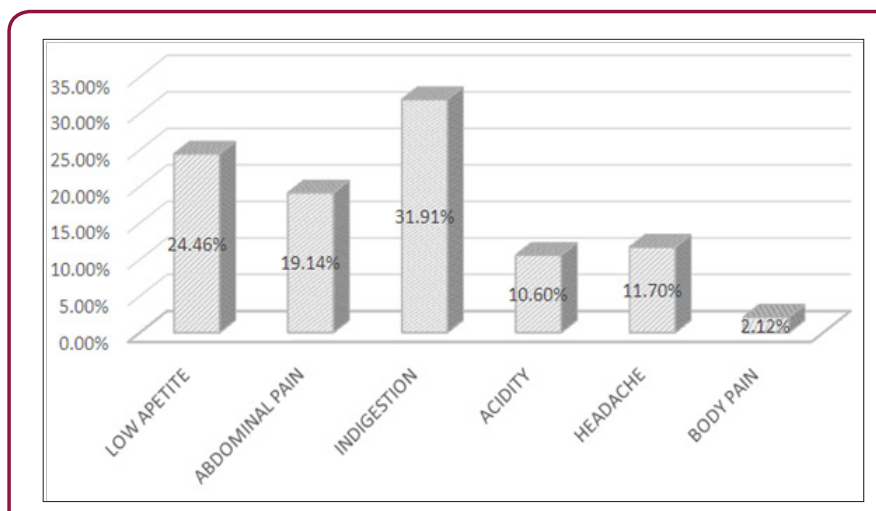

Figure 4: Frequency of H. pylori on the basis of symptoms.

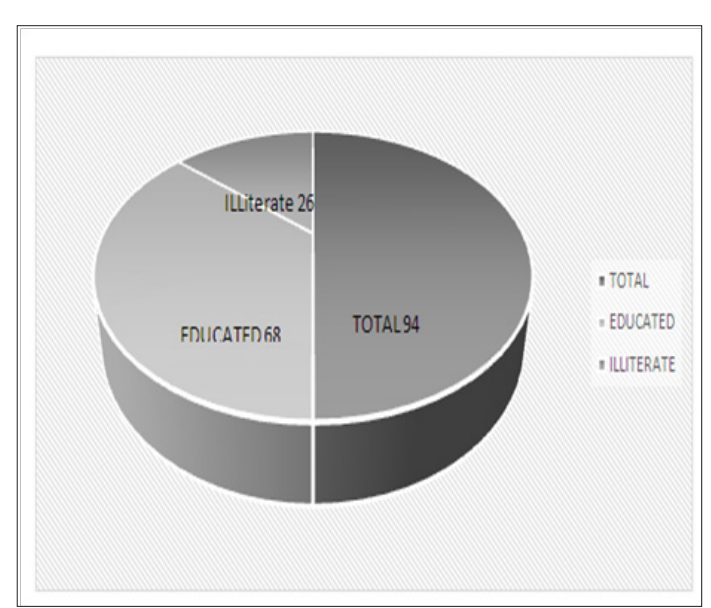

Figure 5: Frequency of H. pylori on basis of Literacy Rate.

\section{Discussion}

Helicobacter pylori are responsible for the most commonly found infection in the world's population. It is the major causative factor for gastric cancer, duodenal ulcers and atrophic gastritis 
that carries significantly mortality, morbidity and health care resource utilization. It is considered to be a major public health issue worldwide. Global systematic review shows that in 2015, worldwide approximately 4.4 billion individuals were estimated to be positive for $\mathrm{H}$. pylori which is the most comprehensive and upto-date systematic review of the worldwide prevalence of $\mathrm{H}$. pylori infection. This study demonstrated that prevalence of H. pylori was $47 \%$ in Mardan which shows contradiction to previous studies. Prevalence of $\mathrm{H}$. pylori was $60 \%$ in Japan studied by Neishis et al. [16]. In 2003 and $84.2 \%$ in Portugal studied by Bastos et al. [17]. In 2013 which was higher than our study. Some studies had low prevalence rate as $27.6 \%$ in England reported by Moayyedi et al. [18] and Lane et al. [19]. In UK where prevalence rate was 15.5\%.

Age distribution of $\mathrm{H}$. pylori infection showed a trend towards decrease in infection with age from young (43\%) to middleaged $(10.6 \%)$, then decreases in the elderly $(2.12 \%)$. This was consistent with previous studies. A marked reduction in the prevalence of infection was previously reported in elderly people $[20,21]$ and in Europe [22]. where prevalence rate increased in younger ages. Educational status has been used as a proxy marker of socio economic status and an important to determinant of $\mathrm{H}$. pylori prevalence. The prevalence of $\mathrm{H}$. pylori was high $(28.9 \%)$ in low educated [23] but our study was in contradiction to them with respect of high prevalence in educated people. In our study prevalence of $\mathrm{H}$. pylori infection appeared higher in males $67 \%$ than females $32.9 \%$. This finding is in agreement with previous $[24,25]$. And in Japan where prevalence rate was higher in men than women and increased with age in Japan [26]. Another recent metaanalysis by [27].

Showed that males were infected more than females, both in children and adults. In H. pylori infection Gender disparity is an intriguing topic, as gastric adenocarcinoma shows significant male predominance. In a Scottish population-based study, the nature of the male predominance of gastric cancer was explored in which they showed that there is a 17-year delay in development of cancer in females. This predominance in males was due to intestinal subtype of adenocarcinoma, which had a strong link to H. pylori infection. There is a significant male predominance in gastric intestinal metaplasia when precancerous lesions were examined but not so in atrophic gastritis. Gender disparity not shown strong link to chronic gastritis induced by $\mathrm{H}$. pylori. These areas need to be explored deeply by taking gender as a consideration factor so it may be helpful to health authorities to tailor their preventive measures. In contrast, another study [28]. Indicated higher prevalence of $\mathrm{H}$. pylori in females compared with males.

A strong association between $\mathrm{H}$. pylori and socioeconomic status, poverty or social deprivation has been reported consistently for many years12. The risk factors which we found from our study was poor living conditions of the $\mathrm{H}$. pylori subjects and the same risk factor was also observed [29]. In a study from Brazil who reported that increased $\mathrm{H}$. pylori infection with a larger number of siblings, nursery schooling, and housing in a street without paved roads and without flushed toilets indicating impoverished living conditions associated with poorer sanitation and overcrowding to be risk factors for $\mathrm{H}$. pylori infection. Our finding showed that $\mathrm{H}$. pylori infection is associated with age and gender. A previous study [30]. Showed no association of $\mathrm{H}$. pylori with gender and age in adults. In contrast, another study [31]. Reported strong association of $\mathrm{H}$. pylori infection with age and sex. The current frequency of $\mathrm{H}$. pylori is reported to be higher among patients in Mardan. There had been a striking increase of H. pylori prevalence rate in males, younger and educated subjects in the study area. This study will be helpful for making strategies and planning to reduce and control this infection in the country.

\section{References}

1. Yan TL, Hu QD, Zhang Q Li YM, Liang TB (2013) National rates of Helicobacterpylori recurrence are significantly and inversely correlated with human development index. Aliment Pharmacol Ther 37(10): 963968.

2. Estakhri R, Dolatkhah H, Ghazanchaei A, Pourasgari B, Nourazarian $M$, et al. (2008) Saliva or serum, which is better for the diagnosis of gastric Helicobacter pylori infection? Iran J Clin Infect Dis 3(3): 121-125.

3. Kusano C, Gotoda T, Ishikawa H, Moriyama M (2017) The administrative project of Helicobacter pylori infection screening among junior high school students in an area of Japan with a high incidence of gastric cancer. Gastric Cancer 20(1): 16-19.

4. Ravelomanana L, Imbert P, Kalach N, Ramarovavy G, Richard V, et al. (2013) Helicobacterpylori infection in children in Madagascar: risk factors for acquisition. Trop Gastroenterol 34(4): 244-251.

5. Ahmad T, Sohail K, Rizwan M, Mukhtar M, Bilal R, et al. (2009) Prevalenceof Helicobacter pyloripathogenicity associated cagA and vacA genotypes among Pakistani dyspeptic patients. FEMS Immunol Med Microbiol 55(1): 34-38.

6. Mehmood K, Hameed Z, Shoukat S, Hasan F, Alam AY, et al. (2011) Predictors of depression in patients presenting with dyspeptic symptoms in a GI clinic. J Ayub Med Coll Abbottabad 23(4): 49-52.

7. Frenck RW, Fathy HM, Sherif M, Mohran Z, El Mohammedy H, et al. (2006) Sensitivity and specificity of various tests for the diagnosis of Helicobacterpylori in Egyptian children. Pediatr 118(4): 1195-1202.

8. Ferro A, Peleteiro B, Malvezzi M, Bosetti C, Bertuccio P, et al. (2014) Worldwide trends in gastric cancer mortality (1980-2011), with predictions to 2015, and incidence by sub type. Eur J Cancer 50(7): $1330-1344$

9. Okuda M, Miyashiro E, Booka M, Tsuji T, Nakazawa T (2007) Helicobacterpylori colonization in the first 3 years of life in Japanese children. Helicobacter 12(4): 324-327.

10. Goh KL,ChanWK,ShiotaS, YamaokaY(2011)Epidemiology ofHelicobacter pylori infection and public health implications. Helicobacter 16(1): 1-9.

11. Rasmussen LT, Labio RW, Gatti LL, Silva LC, Queiroz VF, et al. (2010) Helicobacter pylori detection in gastric biopsies, saliva and dental plaque of Brazilian dyspeptic patients. Mem Inst Oswaldo Cruz 105(3): 326-330.

12. Silva DG, Tinoco EM, Rocha GA, Rocha AM, Guerra JB, et al. (2010) Helicobacter pylori transiently in the mouth may participate in the transmission of infection. Mem Inst Oswaldo Cruz 105(5): 657-660.

13. Kim DH, Jung HM, Hwang YJ, Ahn YS, Mun JS, et al. (2010) Culture and polymerase chain reaction of Helicobacter pylori from rectal and terminal ileal fluid after polyethylene glycol (colyte) ingestion in healthy adults with positive urea breath test. Korean J Gastroenterol 56(1): 2732. 
14. Hu LT, Mobley HL (1993) Expression of catalytically active recombinant Helicobacterpylori urease at wild-type levels in Escherichia coli. Infect Immun 61(6): 2563-2569.

15. Koletzko S, Jones NL, Goodman KJ, Gold B, Rowland M, et al. (2011) Evidence- based guidelines from ESPGHAN and NASPGHAN for Helicobacter pylori infection in children. J Pediatr Gastroenterol Nutri 53(2): 230-243.

16. Nishise Y, Fukao A, Takahashi T (2003) Risk factors for Helicobacter pylori infection among a rural population in Japan: relation to living environment and medical history. J Epidemiol 13(5): 266-273.

17. Bastos J, Peleteiro B, Barros R, Alves L, Severo M, et al. (2013) Sociodemographic determinants of prevalence and incidence of Helicobacter pylori infection in Portuguese adults. Helicobacter 18(6): 413-422.

18. Moayyedi P, Axon AT, Feltbower R, Duffett S, Crocombe W, et al. (2002) Relation of adult lifestyle and socioeconomic factors to the prevalence of Helicobacter pylori infection. Int J Epidemiol 31(3): 624-631.

19. Lane JA, Murray LJ, Harvey IM, Donovan JL, Nair P, et al. (2011) Randomized clinical trial: Helicobacter pylori eradication is associated with a significantly increased body mass index in a placebo-controlled study. Aliment Pharmacol Ther 33(8): 922-929.

20. Neri MC, Lai L, Bonetti P, Baldassarri AR, Monti M, et al. (1996) Prevalence of Helicobacter pylori Infection in Elderly Inpatients and in Institutionalized Old People: Correlation with Nutritional Status. Age Ageing 25(1): 17-21.

21. Salles Montaudon N, Dertheil S, Broutet N, Gras N, Monteiro L, et al. (2002) Detecting Helicobacter pylori infection in hospitalized frail older patients: The Challenge. J Am Geriatr Soc 50(10): 1674-1680.

22. Roberts SE, Morrison RS, Samuel DG, Thorne K, Akbari A, et al. (2016) The prevalence of Helicobacter pylori and the incidence of gastric cancer across Europe. Aliment Pharmacol Ther 43(3): 334-345.

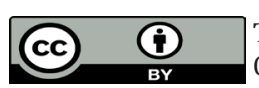

This work is licensed under Creative Commons Attribution 4.0 License

Submission Link: https://biomedres.us/submit-manuscript.php
23. Nguyen TH, Ramsey D, Graham DY, Shiota S, Shaib Y, et al. (2015) The Prevalence of Helicobacter Pyloriremains High in African-american and Hispanic Veterans. Helicobacter 20(4): 305-315.

24. Alo MN, Alhassan HM, Saidu AY, Ugah UI, Anyim C (2013) The Prevalence of Helicobacter pylori Infection in Asymptomatic Persons in Ethiope East Local Government Area of Delta State, Nigeria. Int J Pharm Pharm Sci 1: 115-119.

25. Saidu AY, Munir G, Salihu YN, Sani M, Muhammad Y, et al. (2015) Sero prevalence of Helicobacter pylori among Adult in Sokoto Metropolis. IOSR J Nursing Health Sci 4(5): 64-69.

26. Ueda J, Gosho M, Inui Y, Matsuda T, Sakakibara M, et al. (2014) Prevalence of Helicobacter pylori infection by birth year and geographic area in Japan. Helicobacter 19(2): 105-110.

27. Ibrahim A, Morais S, Ferro A, Lunet N, Peleteiro B (2017) Sex-differences in the prevalence Helicobacter pylori infection in pediatric and adult populations: systematic review and meta-analysis of 244 studies. Dig Liver Dis 49(7): 742-749.

28. Jemikajah DJ, Okogun GRA (2014) Health Point: Prevalence of Helicobacter pylori in Central Hospital, Warri, Nigeria. Afr J Cell Path 3: 57-60.

29. Dattoli VC, Veiga RV, Da Cunha SS, Pontes de Carvalho LC, Barreto ML, et al. (2010) Seroprevalence and potential risk factors for Helicobacter pylori infection in Brazilian children. Helicobacter 15(4): 273-278.

30. Shi R, Xu S, Zhang H, Ding Y, Sun G, et al. (2008) Prevalence and Risk Factors for Helicobacter pylori Infection in Chinese Populations. Helicobacter 13(2): 157-116.

31. Malcolm CA, MacKay WG, Shepherd A, Weaver LT (2004) Helicobacter pylori in Children Is Strongly Associated with Poverty. Scott Med J 49(4): 136-138.

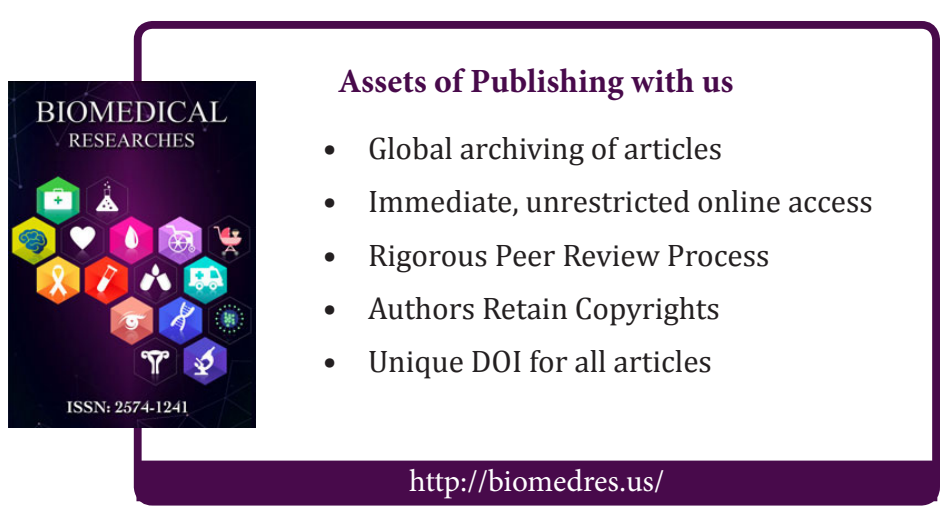

